The North Atlantic Warming Hole as Part of a Century-Long Fluctuating Phenomenon

\author{
Arnold H. Taylor \\ Plymouth Marine Laboratory \\ Prospect Place, West Hoe \\ Plymouth, PL1 3DH, England, U.K. \\ aht@pml.ac.uk
}

This is a non-peer reviewed preprint submitted to EarthArXiv, 


\begin{abstract}
Despite global warming, a region of the North Atlantic has been observed to cool, a phenomenon known as the North Atlantic Warming Hole (NAWH). The causes of the NAWH remain under debate but its emergence has been linked to a slowdown of the meridional circulation leading to a reduced ocean heat transport into the warming hole region. This note uses previously published evidence to suggest that the pattern of temperature change is not unique but may have been a recurring feature during the last century and a half, fluctuating between a positive and negative phase. It appears global warming has amplified one of these phases in the North Atlantic climate.
\end{abstract}

\title{
North Atlantic Temperature Patterns
}

A North Atlantic Warming Hole has been predicted by climate models during the 21 st century. However, much earlier studies of Atlantic surface temperatures have shown a similar feature occurring in the past. This mode of the North Atlantic surface temperatures is shown in Fig.1 (redrawn from Taylor, 1978 and Colebrook and Taylor, 1979). The numbers on Fig. 1a are the weightings in the first principal component obtained from monthly temperature anomalies (1951-1974) at the nine former North Atlantic Ocean Weather stations. The principal component accounts for $29 \%$ of the variance of the temperature anomalies. The contoured and hatched data on which they are superimposed are the results of a similar analysis of temperature anomalies (1966-74) in $2^{\circ}$ longitude $x 1^{\circ}$ latitude rectangles. In each case the pattern represents the dominant mode of variation in the data, temperatures at positive values north and south tending to rise while those at negative values in the centre are falling. At other times during the variation of the component the rises and falls of temperature will be reversed. Throughout the quarter century of the data in Fig, 1a both patterns of temperature occurred with similar frequency (Taylor, 1978, Fig. 3a). A similar non-seasonal first eigenvector was reported by Weare (1977) based on monthly temperatures between $70^{\circ} \mathrm{N}$ and $30^{\circ} \mathrm{S}$ for the years 1949 to 1969. 

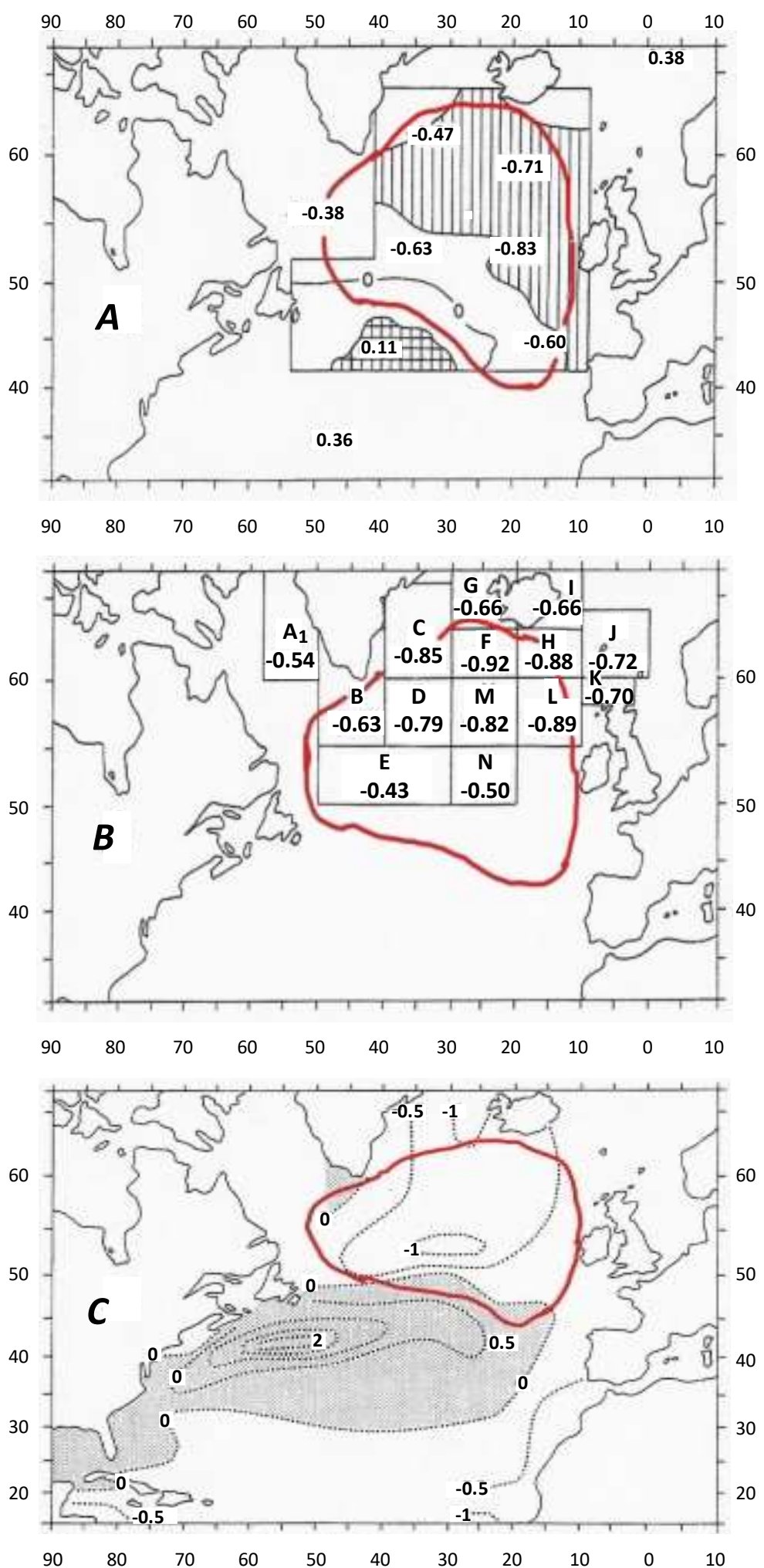

Fig. 1 a: Comparison between the first principal component of temperature anomalies (after removing the seasonal cycle) at the nine Ocean Weather Stations (1951-1974) and the component obtained from synoptic data (1966-1974). The vertical hatching represents values less than -0.48 and the cross hatching values greater than +0.48 , the zero contour is also given. b: The first principal component obtained from Smed's time-series for 1876-1961. c: Change 
of Atlantic surface temperature between 1894-98 and 1920-24 redrawn from Bjerknes (1964). In each chart the outline of the NAWH (shown in red) encloses the negative values.

The red loop on Fig. 1a shows that the outline of the NAWH (Keil et al., 2020; Rahmstorf et al., 2015) encloses the negative values. Recent temperatures in this region have cooled or hardly risen while those among the positive numbers to the north and south have risen. In an attempt to extend this result further back in time, Fig. 1b (redrawn from Taylor, 1978) shows the first principal component of annual temperatures from 1876 to 1961 published by Smed (1965) for a number of areas covering most of the region $50^{\circ} \mathrm{N}$ to $67^{\circ} \mathrm{N}, 0^{\circ}$ to $58^{\circ} \mathrm{W}$. The spatial coverage does not extend outside the NAWH, but the weightings are all of the same sign and peak in magnitude towards its centre. The dominant pattern in Smed's data has this region fluctuating as a whole between positive and negative values (Colebrook and Taylor, 1979, Fig. $2 \mathrm{~b})$. The conjecture that the pattern in Fig. $1 \mathrm{~b}$ is part of the mode of variation in Fig. 1a is supported by Bjerknes (1964) plot of the temperature change between 1894-1898 and 19201924 (Fig. 1c), which shows that the fall in temperature in Smed's regions was accompanied by a rise in temperature to the south. Similar or inverse patterns were presented by Bjerknes for the late 1920s and early 1930s.

\section{Discussion}

The distributions of temperature change in Fig 1 therefore suggest that the NAWH could be an enhanced negative phase of this North Atlantic mode caused by anthropogenic warming (Chemke et al., 2020). If so, the processes responsible must be similar to, albeit considerably stronger than, those operating during the century covered by the data in Fig. 1. In this earlier period, they also must sometimes have operated in reverse. Explaining the NAWH requires both atmospheric and oceanic mechanisms. Keil et al. (2020) have shown that reduced lowlatitude import, increased ocean heat transport out of the region into higher latitudes and a shortwave cloud feedback dominate the formation and temporal evolution of the warming hole under greenhouse gas forcing. When the early observations reported here have been improved by an analysis of the more complete data sets now available, they may provide an extended context and constraints for examination of these processes. The mode in Fig.1 flipped between positive and negative phases on a time-scale of a few years which could make more slowly operating ocean processes less likely. In addition, there are model results showing that the NAWH can play an important role in the atmospheric circulation and midlatitude jets (Gervais et. al., 2019. Did this happen in the past with the weaker patterns of Fig. 1?

\section{References}

Bjerknes, J. Atlantic air-sea interaction. Adv. Geophys., 10, 1-82 (1964).

Colebrook, J.M. \& Taylor, A.H. Year-to-year changes in sea-surface temperature, North Atlantic and North Sea, 1948 to 1974. Deep-Sea Res., 26A, 825-850 (1979).

Chemke, R., Zanna, L. \& Polvani, L.M. Identifying a human signal in the North Atlantic warming hole. Nature Communs., 11, 1540, (2020). 
Gervais, M. et al. Impacts of the North Atlantic Warming Hole in future climate projections: mean atmospheric circulation and the North Atlantic jet. J. Clim., 15 May, 2673-2689 (2019).

Keil, P. et al. Multiple drivers of the North Atlantic warming hole. Nature Climate Change, 10, 667-671 (2020).

Rahmstorf S. et al. Exceptional twentieth-Century slowdown in Atlantic Ocean overturning circulation. Nature Climate Change (online) (2015).

Smed J. Variation of the temperature of the surface water in areas of the northern North Atlantic, 1876-1961. Spec. Publs. Int. Commun. N. W. Fish., 6, 821-826 (1965)

Taylor, A.H. Long-term changes in the North Atlantic current system and their biological implications. Proc. Roy. Soc. Edinb., 76B, 223-243 (1978).

Weare, B.C. Empirical orthogonal analysis of sea surface temperature. J. Phys. Oceanogr., 6, 671-678 (1977). 